\title{
Mechanistic Analysis of Cellular Internalization of a Cell- and Skin-Penetrating Peptide
}

\author{
Michael Zakrewsky $^{1}$ - John A. Muraski ${ }^{1} \cdot$ Samir Mitragotri $^{1}$
}

Received: 1 November 2015 / Accepted: 20 February 2016 / Published online: 8 March 2016

(C) The Regenerative Engineering Society 2016

\begin{abstract}
Background Keratinocytes are a targeted cell-type for treating skin disease. However, delivering drugs into the skin and keratinocytes remains challenging due to transport barriers posed by both the stratum corneum and cell membrane. Nonetheless, SPACETM peptide has been shown effective in delivering a number of macromolecules into the skin and cells. Accordingly, we sought to explore the mechanism of SPACE ${ }^{\mathrm{TM}}$ peptide internalization under conditions relevant for skin delivery.

Methods Mechanistic analysis was performed using live cell confocal microscopy. Potential binding targets were assessed by Western blot and mass spectrometry.

Results Experimental data suggest an energy-dependent mechanism for the cellular entry of SPACETM peptide into human epidermal keratinocytes. SPACETM peptide associates with the cell membrane within seconds and then is internalized rapidly. Co-incubation with heparin sulfate or serum suggests that association with the cell membrane may be specific in nature. Western blot and mass spectrometry studies are consistent with earlier findings that keratin may play an important role in SPACE ${ }^{\mathrm{TM}}$ peptide internalization.

Conclusions This work highlights the potential for delivering drug into the cytoplasm of keratinocytes for the treatment of skin disease through topical application. Further, it highlights an ongoing need for studies involving cell-penetrating peptides under clinically relevant conditions.
\end{abstract}

Samir Mitragotri

samir@engineering.ucsb.edu

1 Center for Bioengineering, Department of Chemical Engineering, University of California, Santa Barbara, CA 93106, USA
Lay Summary SPACE ${ }^{\mathrm{TM}}$ peptide has been shown to enhance delivery of a wide variety of macromolecules into the skin and cells. However, the mechanism of cell entry of SPACETM peptide under conditions relevant for skin delivery is not understood. Accordingly, we sought to explore the mechanism of SPACETM peptide internalization in keratinocytes under conditions relevant for skin delivery. A better understanding of the dominating pathways and major molecular players involved in SPACE ${ }^{\text {TM }}$ peptide internalization under clinically relevant conditions will aid the development and translation of SPACE ${ }^{\mathrm{TM}}$ peptide-based technologies for treating skin disease.

Keywords SPACE ${ }^{\mathrm{TM}}$ peptide $\cdot$ Cell-penetrating peptide . Skin $\cdot$ Cell internalization $\cdot$ Drug delivery

$\begin{array}{ll}\text { Abbreviations } \\ \text { SC } & \text { Stratum corneum } \\ \text { FITC } & \text { Fluorescein isothiocyanate } \\ \text { HEKa } & \text { Human adult epidermal keratinocyte } \\ \text { HBSS } & \text { Hank's balanced salt solution } \\ \text { EtBr } & \text { Ethidium bromide } \\ \text { FBS } & \text { Fetal bovine serum } \\ \text { TAMRA } & \text { Tetramethylrhodamine } \\ \text { EIPA } & \text { 5-(N-Ethyl-N-isopropyl)amiloride } \\ \text { M } \beta C D & \text { Methyl- } \beta \text {-cyclodextrin } \\ \text { EGF } & \text { Epidermal growth factor } \\ \text { CPP } & \text { Cell-penetrating peptide }\end{array}$

\section{Introduction}

Keratinocytes are the major cell-type present in human viable skin tissue [1], and therefore, are considered a primary target for treating skin-resident disease [1, 2]. Several 
dermatological conditions including psoriasis [2], atopic dermatitis [3], wound healing [4, 5], and bullous impetigo [6] manifest clinical symptoms due to abnormal keratinocyte function or behavior, and therapies that target keratinocytes have shown promise [7, 8]. Unfortunately, however, delivery of drugs into keratinocytes is inherently difficult. Systemic approaches for drug delivery to keratinocytes are limited by drug degradation in the GI tract, limited accumulation in the dermis and epidermis, and systemic toxicity [9]. Topical delivery methods can potentially address this challenge; however, cutaneous drug delivery remains difficult due to barrier properties of the outermost layer of the skin - the stratum corneum (SC) [10]. Further, the cell membrane of keratinocytes can pose an additional significant transport barrier, and intracellular sequestration by trafficking machinery can severely limit bioavailability at the drug target site [11].

To overcome these challenges, peptides have emerged as a promising strategy for simultaneous enhancement of drugs across multiple biological barriers including the SC and cell membrane [12-15]. In particular, SPACETM peptide has been demonstrated effective at delivering a wide variety of macromolecules including cyclosporine A [16], hyaluronic acid [17], and siRNA [18] into skin and cells, and extensive efforts have been spent on identifying its mechanism of skin penetration enhancement [19]. However, the mechanism of cell entry of SPACE ${ }^{\mathrm{TM}}$ peptide under conditions relevant for skin delivery is not understood. Accordingly, we sought to explore the mechanism of SPACETM peptide internalization in keratinocytes under conditions relevant for skin delivery. A better understanding of the dominating pathways and major molecular players involved in SPACE ${ }^{\mathrm{TM}}$ peptide internalization under clinically relevant conditions will aid the development and translation of SPACETM peptide-based technologies for treating skin disease. Here, we report evidence of an energy-dependent mechanism for drug delivery by SPACETM peptide directly into the cytoplasm of human epidermal keratinocytes.

\section{Materials and Methods}

\section{SPACE ${ }^{\text {TM }}$ Peptide}

Fluorescein isothiocyanate (FITC) was used as a model membrane-impermeable small molecule drug. FITClabeled SPACETM peptide (FITC-AC-TGSTQHQ-CG, Disulfide Bridge 2-10) was purchased from RS Synthesis, LLC (Louisville, KY). Final composition and purity was confirmed by RS Synthesis, LLC prior to shipment. FITCSPACE ${ }^{\mathrm{TM}}$ peptide composition was determined by mass spectrometry, and peptide purity of $99.1 \%$ was determined by HPLC.

\section{Cell Culture}

Human adult epidermal keratinocytes (HEKa cells) and cell culture materials were acquired from Life Technologies (Grand Island, NY). HEKa cells were cultured in $1 \times$ keratinocyte serum-free medium supplemented with $25 \mathrm{U} /$ $\mathrm{mL}$ penicillin, $25 \mu \mathrm{g} / \mathrm{mL}$ streptomycin, and $50 \mu \mathrm{g} / \mathrm{mL}$ neomycin. Cultures were grown at $37{ }^{\circ} \mathrm{C}$ with $5 \% \mathrm{CO}_{2}$.

\section{Cell Internalization}

Cells were seeded on poly-d-lysine-coated glass bottom culture dishes (MatTek Corporation, Ashland, MA) and were allowed to attach and proliferate until $\sim 80 \%$ confluency under standard culture conditions $\left(37{ }^{\circ} \mathrm{C}\right.$ with $\left.5 \% \mathrm{CO}_{2}\right)$. Then, media was removed and $50 \mu \mathrm{L}$ of fluorescent peptide solution in culture media was added to the cell culture dish. As a control, an equivalent amount of media was added in place of peptide solution. Cells were incubated at $37^{\circ} \mathrm{C}$ unless otherwise specified, after which the fluorescent solution was removed and cells were prepared for confocal microscopy.

\section{Confocal Microscopy}

After incubation with FITC-SPACE ${ }^{\text {TM }}$ peptide or control solution, cells were incubated with $5 \mu \mathrm{g} / \mathrm{mL}$ Hoechst 33342 (Life Technologies, Grand Island, NY) for $5 \mathrm{~min}$ at room temperature and then washed with supplemented Hank's Balanced Salt Solution (HBSS, Lonza Group Ltd., Basel, Switzerland). HBSS was supplemented with $200 \mu \mathrm{M}$ Trolox (Sigma, St. Louis, MO) to limit phototoxicity and photobleaching during imaging. Cells were washed with supplemented HBSS three times for 5 min each. The cell culture dishes were then filled with $90 \mu \mathrm{M}$ ethidium bromide (EtBr, Life Technologies, Grand Island, NY) in supplemented HBSS and imaged using a confocal laser scanning microscope (Olympus Fluoview 1000S, Olympus, Center Valley, PA); $90 \mu \mathrm{M} \mathrm{EtBr}$ was sufficient to quench any significant fluorescence from externally bound FITC-SPACE ${ }^{\mathrm{TM}}$ peptide. All instrument settings were kept constant to enable comparisons between experimental conditions, and a $\times 30$ silicon immersion objective was used to capture the entire thickness of the cell. Dead cells indicated by EtBr staining of the nucleus were ignored during analysis.

\section{Image Analysis}

Image analysis was performed using Fiji to determine the overall fluorescence intensity for each cell. For localization studies a $\times 60$ silicon immersion objective was used. Five to seven slices were taken at $500-\mu \mathrm{m}$ intervals and analyzed in CellProfiler [20]. Briefly, unaltered greyscale confocal images were loaded. Optimized-thresholding was used to segment 
cell nuclei. The cell outline was then determined by expanding from the centroids of the cell nuclei until the variance between the fluorescence intensities of the cell and local background was minimized. Lastly, vesicles were segmented using an optimized-thresholding algorithm with size, shape, and position constraints. After segmentation, controls were subtracted and various quantitative information, e.g., vesicle intensities, cytoplasm intensity, vesicle location, and vesicle distribution from nucleus were collected and analyzed.

\section{Membrane Association}

SPACETM peptide association with the cell membrane was assessed with confocal microscopy. Nuclei were stained with Hoechst 33342, and cells were focused on using brightfield and Hoechst channel. The PMT for the FITC channel was adjusted, so $10 \mathrm{mg} / \mathrm{mL}$ FITC-SPACETM peptide in solution was not detected. Then, $10 \mathrm{mg} / \mathrm{mL}$ FITC-SPACETM peptide was added to the culture dish and images were taken every $2 \mathrm{~s}$ for $2 \mathrm{~min}$.

The specificity of SPACETM peptide association with the cell membrane was explored by co-incubation of FITCSPACETM peptide with molar excess heparin sulfate (SigmaAldrich, St. Louis, MO) or fetal bovine serum (FBS, Sigma Aldrich, St. Louis, MO). $2 \times$ molar excess of heparin sulfate was used to compete with non-specific electrostatic interactions. 10× excess weight of total protein of FBS was used to compete with non-specific protein interactions. Cells were incubated for $1 \mathrm{~h}$ with solutions of heparin sulfate or FBS in media. Media alone was used as a control. Simultaneously, FITC-SPACE ${ }^{\mathrm{TM}}$ peptide was incubated for $1 \mathrm{~h}$ with heparin sulfate or FBS. Media alone was used as a control. After $1 \mathrm{~h}$ incubation, media, heparin sulfate, and FBS solutions were removed from the cell culture dishes and replaced with the solutions of FITC-SPACETM peptide incubated with heparin sulfate, FBS, or media alone. Cell internalization was then determined as described above.

\section{Protein Purification}

Protein from cell lysate was purified using the Membrane I, ReadyPrep ${ }^{\mathrm{TM}}$ Protein Extraction Kit, and 2-D Cleanup Kit (Bio-Rad Laboratories, Hercules, CA) according to the manufacturers recommended protocol. Briefly, cells were detached from the culture flask with StemPro ${ }^{\circledR}$ Accutase $^{\circledR}$ (Life Technologies, Grand Island, NY), centrifuged to isolate the cell pellet, and then re-suspended in extraction buffer supplemented with Protease Inhibitor Cocktail (Sigma-Aldrich, St. Louis, MO). StemPro ${ }^{\circledR}$ Accutase $^{\circledR}$ is a gentle cell dissociation reagent, and was used to limit digestion of extracellular proteins during detachment. Cells were then lysed with a Misonix Sonicator ${ }^{\circledR} 3000$ cycled on/off for 1 min each. The cell suspension was maintained on ice to avoid overheating. After lysing, proteins were fractionated into water-soluble (e.g., cytosolic proteins), surfactant-soluble (e.g., hydrophobic proteins, membrane proteins), and insoluble (e.g., multitransmembrane proteins, filamentous proteins) fractions. The amount of protein in each fraction was quantified using the RC DC Protein Assay (Bio-Rad Laboratories, Hercules, CA).

\section{SDS-PAGE and Western Blot}

Cell lysate fractions were diluted to equate protein concentration in each fraction and then dissolved in Laemmli sample buffer (Bio-Rad Laboratories, Hercules, CA) with $355 \mathrm{mM} \beta$ mercaptoethanol. Protein fractions were run on a Criterion ${ }^{\mathrm{TM}}$ TGX Stain-Free ${ }^{\mathrm{TM}}$ AnykD ${ }^{\mathrm{TM}}$ Precast Gel (Bio-Rad Laboratories, Hercules, CA) following the manufacturers recommended protocol. In addition, a Precision Plus Protein ${ }^{\mathrm{TM}}$ WesternC ${ }^{\text {TM }}$ standard was run to determine approximate molecular weights of sample protein bands. Ladder and all fractions were run in duplicate. After SDS-PAGE, gels were removed from their cassette. One set of ingel ladder and fractions was set aside to provide samples for mass spectrometry. The second set was imaged using the Bio-Rad ChemiDoc ${ }^{\mathrm{TM}}$ XRS + System and Image $\mathrm{Lab}^{\mathrm{TM}}$ software. The default stain-free gel workflow with minimal exposure was used for imaging SDS-PAGE gels to allow subsequent transfer of protein to a Western blot membrane.

After imaging, protein was transferred to a PVDF membrane using the Trans-Blot ${ }^{\circledR}$ Turbo $^{\text {TM }}$ Transfer System (BioRad Laboratories, Hercules, CA) according to the manufacturers recommended protocol. The membrane was blocked with $5 \%$ dry milk in Tris-buffered saline with tween-20 (TBST) overnight at $4{ }^{\circ} \mathrm{C}$. Then, the membrane was washed with TBST and incubated with $10 \mu \mathrm{g} / \mathrm{mL}$ FITC-SPACE ${ }^{\mathrm{TM}}$ peptide in TBST with $1 \%$ dry milk for $1 \mathrm{~h}$. After incubation, the membrane was washed and imaged using the Bio-Rad ChemiDoc ${ }^{\mathrm{TM}}$ XRS+ System and Image Lab ${ }^{\mathrm{TM}}$ software. Default FITC filter set was used, and exposure was adjusted automatically for the best resolution of protein bands with bound FITC-SPACETM peptide. After imaging, the unused SDS-PAGE samples were aligned with the PVDF membrane, and gel bands corresponding to FITC-SPACETM peptide binding were cutout with a sterile surgical scalpel and stored in $1 \mathrm{~mL} \mathrm{ddH_{2 } \mathrm { O }}$ in individual microcentrifuge tubes for analysis via mass spectrometry.

\section{Mass Spectrometry}

In-gel digest, mass spectrometry, and all analysis were performed by MS Bioworks LLC (Ann Arbor, MI). 


\section{Co-Incubation with Dextran}

Co-incubation studies were performed with tetramethylrhodamine-labeled 3000 Da dextran (TAMRAdextran, Life Technologies, Grand Island, NY). $5 \mathrm{mg} / \mathrm{mL}$ TAMRA-dextran was incubated with $10 \mathrm{mg} / \mathrm{mL}$ FITCSPACETM peptide. $5 \mathrm{mg} / \mathrm{mL}$ TAMRA-dextran alone and $10 \mathrm{mg} / \mathrm{mL}$ FITC-SPACETM peptide alone were used as controls. Cell internalization and intracellular localization were determined as described above.

\section{Endocytosis Inhibitors}

The mechanism of SPACETM peptide internalization was explored using endocytosis inhibitors that were previously identified in the literature [21]. Endocytosis inhibitors were acquired from Sigma-Aldrich (St. Louis, MO). Cells were incubated with various endocytosis inhibitors, or at $4{ }^{\circ} \mathrm{C}$, for $1 \mathrm{~h}$ prior to the addition of fluorescently labeled peptide. 5-(NEthyl-N-isopropyl)amiloride (EIPA), cytochalasin D, nocodazole, dynasore, genistein, and monodansylcadaverine were dissolved in DMSO and then diluted in media to a concentration of $100 \mu \mathrm{M}, 1 \mu \mathrm{g} / \mathrm{mL}, 5 \mu \mathrm{g} / \mathrm{mL}, 25 \mu \mathrm{g} / \mathrm{mL}$, $200 \mu \mathrm{g} / \mathrm{mL}$, and $200 \mu \mathrm{M}$, respectively. Chlorpromazine, nystatin, methyl- $\beta$-cyclodextrin $(\mathrm{M} \beta \mathrm{CD})$, primaquine, and epidermal growth factor (EGF) were dissolved in media and used at concentrations of $10 \mu \mathrm{g} \mathrm{mL}, 25 \mu \mathrm{g} \mathrm{mL}, 10 \mathrm{mg} / \mathrm{mL}$, $250 \mu \mathrm{g} \mathrm{mL}$, and $100 \mu \mathrm{g} \mathrm{mL}$, respectively. After incubation in the presence of inhibitors for $1 \mathrm{~h}$, a solution of inhibitor at their respective concentration and FITC-SPACE ${ }^{\mathrm{TM}}$ peptide at $10 \mathrm{mg} / \mathrm{mL}$ was added to the culture dish and cell internalization was determined as described above. These studies were also performed using FITC-transferrin $(50 \mu \mathrm{g} / \mathrm{mL}$, Life Technologies, Grand Island, NY) as a model marker of clathrin-mediated endocytosis.

\section{Visualization of Actin and Tubulin}

Actin and microtubules were visualized with confocal microscopy. After incubation with test or control solutions, cells were washed briefly with supplemented HBSS and then fixed for 15 min with $4 \%$ paraformaldehyde (Boston BioProducts, Ashland, MA). After fixation, cells were again briefly washed with supplemented HBSS and then permeabilized with $0.2 \%$ Triton X-100 (Sigma-Aldrich, St. Louis, MO) for $5 \mathrm{~min}$. For visualization of actin, cells were washed three times for $5 \mathrm{~min}$ each, stained with $50 \mathrm{nM}$ rhodamine-phalloidin (Life Technologies, Grand Island, NY) in HBSS, washed again and stained with $5 \mu \mathrm{g} / \mathrm{mL}$ Hoechst 33342 in HBSS for $5 \mathrm{~min}$, washed again three times for $5 \mathrm{~min}$ each in HBSS, mounted in ProLong ${ }^{\circledR}$ Gold (Life Technologies, Grand Island, NY), and imaged. For visualization of tubulin, cells were prepared using tubulin- $\alpha$ polyclonal antibody and the Image-iT" ${ }^{\text {TM }} \mathrm{FX}$ Kit with Alexa Fluor ${ }^{\circledR}$ Secondary Detection Conjugates (Life Technologies, Grand Island, NY) following the manufacturers recommended protocol. Nuclei were then stained with Hoechst 33342 and mounted in ProLong ${ }^{\circledR}$ Gold before imaging.

\section{Statistical Analysis}

Data reported are mean + SD except where otherwise noted. Statistical significance was confirmed by the two-tailed, unpaired Student's $t$ test in Microsoft Excel. The level of significance was set at $p<0.05$.

\section{Results}

\section{Binding and Internalization of SPACE ${ }^{\text {TM }}$ Peptide}

Kinetics of membrane association and internalization of SPACETM peptide by keratinocytes were assessed. These measurements were performed at peptide concentrations in the range of milligram/milliliter to reflect the concentrations of SPACETM peptide used in previous studies that assessed therapeutic applications [16-18]. In this concentration range, SPACE ${ }^{\mathrm{TM}}$ peptide nearly instantaneously bound to the cell membrane (Fig. 1a, saturation after $\sim 1 \mathrm{~min}$ ), while internalization showed slower kinetics (Fig. 1b, saturation after $\sim 30 \mathrm{~min}$ ). Representative images are shown in Fig. 1a (ii)-(v), b (ii)-(iv) for membrane association and cell internalization, respectively. Association of SPACETM peptide with the cell membrane appears to be specific in nature. Incubation with molar excess FBS (to inhibit nonspecific protein binding) and heparin sulfate (to inhibit non-specific electrostatic interactions with the cell membrane) did not decrease internalization of SPACETM peptide (Fig. 1c).

\section{Potential Binding Site of SPACE ${ }^{\text {TM }}$ Peptide}

Potential binding target of SPACETM peptide was identified by protein separation with SDS-PAGE (Fig. 2a) and subsequent Western blot (Fig. 2b). SPACETM peptide is small (11-mer) and cyclic; thus, we expect its relevant binding site to be amino acid residues that are located within close proximity in the primary sequence of its binding target protein. Therefore, the binding site should not be significantly affected by denaturation. Indeed, Western blot yielded three bands corresponding to $\sim 55, \sim 45$, and $\sim 15 \mathrm{kDa}$ molecular weight protein products. Binding was only observed for the insoluble fraction, e.g., multi-transmembrane proteins, cytoskeletal proteins, etc. (Fig. 2b). Mass spectrometry analysis of the three fluorescent bands identified 244 potential binding partners for 
Fig. 1 SPACE ${ }^{\mathrm{TM}}$ peptide association with the cell membrane saturates within $1 \mathrm{~min}$, while internalization saturates after 15-30 min. Competitive binding of SPACE ${ }^{\mathrm{TM}}$ peptide with serum proteins and heparin sulfate indicates cell membrane association may be mediated by a specific binding interaction. a SPACETM peptide association with the cell membrane. $i$ Fluorescence intensity associated with the cell membrane. Error bars represent mean \pm SD for $n=3$. $i i-v$ Representative images showing cell membrane association after ii $0 \mathrm{~s}$, iii $30 \mathrm{~s}$, iv $60 \mathrm{~s}$, and $v 120 \mathrm{~s}$. Nuclei are shown in blue and FITCSPACETM peptide is shown in green. b SPACE ${ }^{\mathrm{TM}}$ peptide internalization. $i$ Fluorescence intensity internalized. Error bars represent mean $\pm \mathrm{SD}$ for $n=3$. $i i-i v$ Representative images showing internalization after $i i$ $5 \mathrm{~min}$, iii $15 \mathrm{~min}$, and $i v 60 \mathrm{~min}$. $\mathrm{c}$ Internalization of FITC-

SPACE ${ }^{\mathrm{TM}}$ peptide was quantified in the presence of excess fetal bovine serum $(F B S)$ or heparin sulfate. Values were normalized to internalization of FITCSPACE ${ }^{\mathrm{TM}}$ peptide in media only. Error bars represent mean + SD for $n=3$ (a)
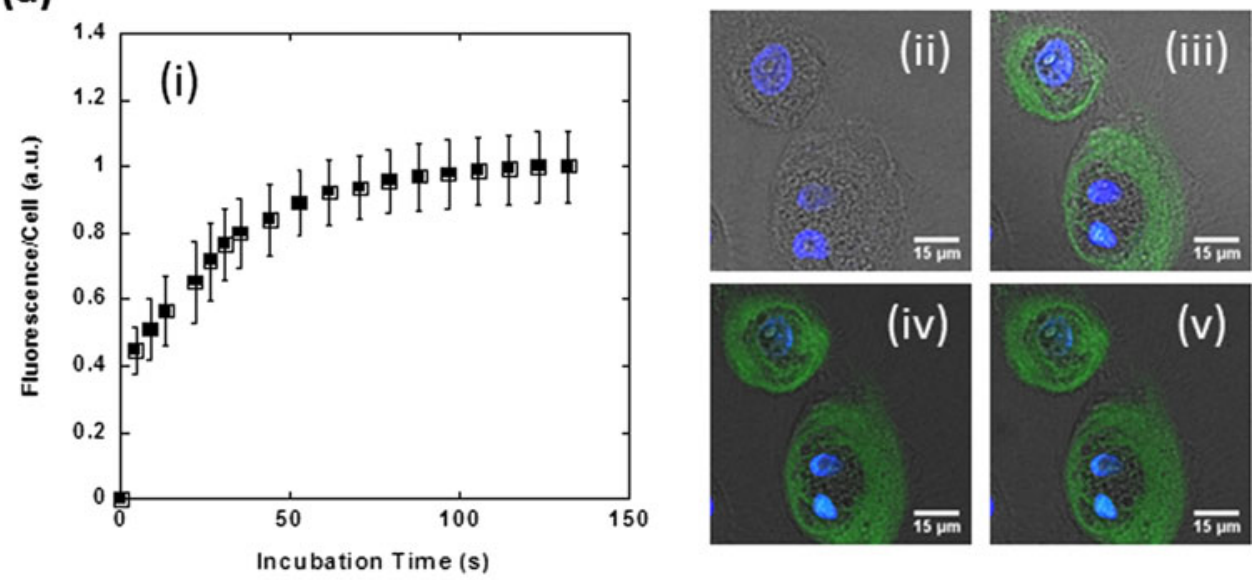

(b)

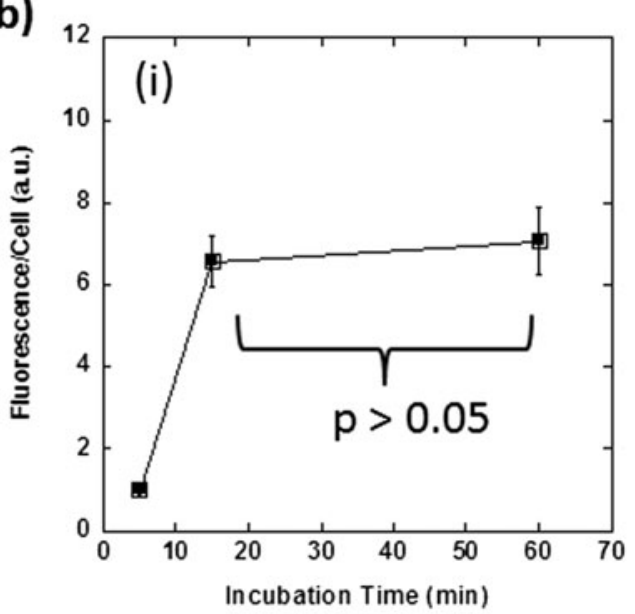

(c)

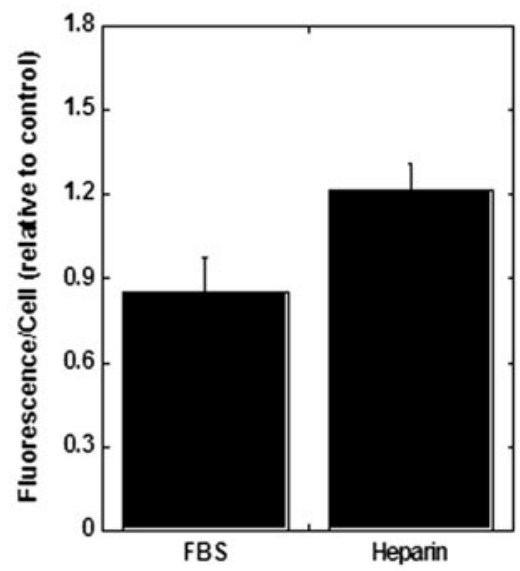

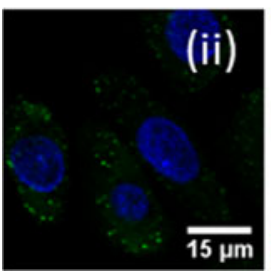
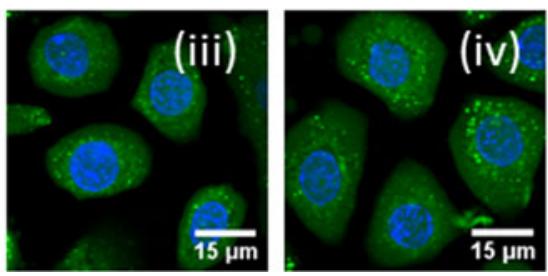

SPACETM peptide. A subset of these potential binding partners based on the counts of corresponding peptide fragments is given (Table 1).

\section{Effect of Energy Depletion on Internalization}

To assess the existence of an energy-dependent mechanism of uptake, internalization at $4{ }^{\circ} \mathrm{C}$ was compared to $37^{\circ} \mathrm{C}$ (Fig. 3). Internalization was nearly completely eliminated at $4{ }^{\circ} \mathrm{C}(95.6$ $\pm 2.5 \%$ and $96.3 \pm 1.0 \%$ reduction in internalization for 15 and $60 \mathrm{~min}$ incubation, respectively) suggesting internalization is energy-dependent (Fig. 3a). This behavior was observed regardless of the length of incubation. Representative images showing internalization at $4{ }^{\circ} \mathrm{C}$ and $37^{\circ} \mathrm{C}$ are given (Fig. 3b (i) and (ii), respectively).

\section{Co-Localization with Dextran}

Internalization of SPACETM peptide at low concentrations $(\mu \mathrm{g} / \mathrm{mL})$ was previously shown to occur through macropinocytosis [12]. Macropinocytosis has also been reported as key for internalization of other CPPs [22-26]. To explore if increased internalization and localization in the cytoplasm at higher concentrations $(\mathrm{mg} / \mathrm{mL})$ was also due to macropinocytosis, dextran was used as a marker. Dextran is considered a marker of macropinocytosis [23], and therefore, if SPACETM peptide is internalized primarily via macropinocytosis, we would expect significant co-localization of SPACE ${ }^{\mathrm{TM}}$ peptide with dextran in macropinosomes. Similarly, if SPACETM peptide perturbs the integrity of macropinosomes leading to endosomal escape 
Fig. 2 SDS-PAGE and Western blot show SPACETM peptide binds to insoluble protein products with $\sim 55, \sim 45$, and $\sim 15 \mathrm{kDa}$ molecular weights. a SDS-PAGE and $\mathbf{b}$ Western blot with cell lysate. Binding of FITCSPACE $^{\mathrm{TM}}$ peptide to protein lanes is indicated by arrows. Protein ladder (lane 1), insoluble proteins (lane 2), water soluble proteins (lane 3), and surfactant soluble proteins (lane 4)

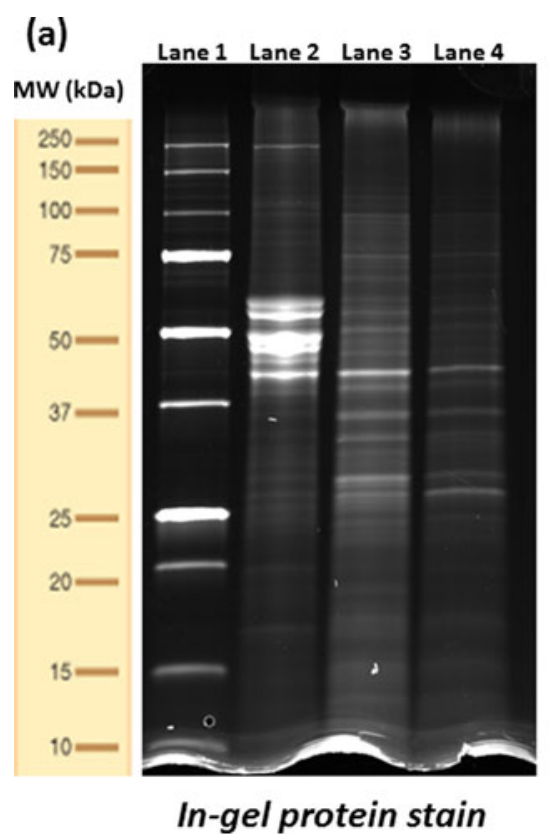

(b)

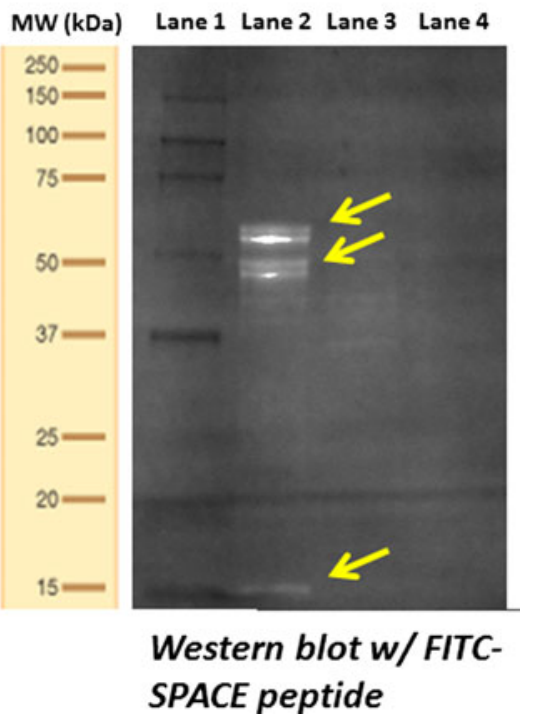

into the cytosol, we would expect dextran might also escape leading to its co-localization with SPACE ${ }^{\mathrm{TM}}$ peptide in the cytosol.

Results show FITC-SPACE ${ }^{\mathrm{TM}}$ peptide indeed co-localizes with TAMRA-dextran; however, dextran remains in punctate structures while SPACETM peptide showed mostly diffuse cytoplasmic staining (Fig. 4a, co-localization indicated by yellow arrows). Additionally, dextran internalization is significantly decreased $(38.1 \pm 12.6 \%)$ when co-incubated with SPACE ${ }^{\text {TM }}$ peptide (Fig. 4b (i), closed bar). Internalization of SPACE ${ }^{\text {TM }}$ peptide, however, was not significantly affected by co-incubation with dextran (Fig. 4b (ii), closed bar). Together, the data suggest that at least a part of SPACETM peptide is internalized by macropinocytosis and competes with dextran internalization via the same pathway.
The occurrence of macropinocytosis was further assessed by observing membrane ruffling (Fig. 5a). Membrane ruffling is characteristic of macropinocytosis stimulation [23]. Surprisingly, SPACE ${ }^{\mathrm{TM}}$ peptide did not initiate actin rearrangement characteristic of macropinocytosis stimulation (Fig. 5a (ii), ruffling indicated by yellow arrows). Moreover, SPACETM peptide internalization actually increased significantly ( $2.4 \pm 0.5$ fold) when macropinocytosis was inhibited with EIPA (Fig. 5b (ii), open bar). Activation of macropinocytosis with EGF did result in membrane ruffling (Fig. 5a (iv), membrane ruffling indicated by yellow arrows) but had no significant effect on SPACETM peptide internalization (Fig. 5b (ii), closed bar). Dextran was used as a control. As expected, dextran did not stimulate micropinocytosis; however,
Table 1 Subset of potential proteins identified by mass spectrometry

\begin{tabular}{lll}
\hline Identified proteins & Accession number & Molecular weight (kDa) \\
\hline Plectin & sp|Q15149|PLEC_HUMAN & 532 \\
Keratin, type II cytoskeletal 5 & sp|P13647|K2C5_HUMAN (+1) & 62 \\
Collagen alpha-1 (XVII) chain & sp|Q9UMD9|COHA1_HUMAN & 150 \\
Vimentin & sp|P08670|VIME_HUMAN & 54 \\
Keratin, type II cytoskeletal 1 & sp|P04264|K2C1_HUMAN & 66 \\
Keratin, type II cytoskeletal 6A & sp|P02538|K2C6A_HUMAN (+1) & 60 \\
Keratin, type I cytoskeletal 14 & sp|P02533|K1C14_HUMAN (+1) & 52 \\
Prelamin-A/C & sp|P02545|LMNA_HUMAN & 74 \\
Tubulin alpha-4A chain & sp|P68366|TBA4A_HUMAN & 50 \\
Actin, cytoplasmic 1 & sp|P60709|ACTB_HUMAN & 42 \\
Keratin, type I cytoskeletal 16 & sp|P08779|K1C16_HUMAN (+2) & 51 \\
Tubulin alpha-1B chain & sp|P68363|TBA1B_HUMAN & 50 \\
Keratin, type II cytoskeletal 6B & sp|P04259|K2C6B_HUMAN & 60
\end{tabular}


Fig. 3 SPACE ${ }^{\mathrm{TM}}$ peptide internalization remains energydependent at high concentrations. a SPACETM peptide

internalization was quantified at 4 and $37^{\circ} \mathrm{C}$. A significant reduction in the amount internalized was observed at $4{ }^{\circ} \mathrm{C}$ compared to $37^{\circ} \mathrm{C}$ for both 15 min incubation (open bars) and 60-minute incubation (closed bars). Error bars represent mean + SD for $n=3 .{ }^{*} p<0.01$. b Representative images of FITC-SPACE ${ }^{\mathrm{TM}}$ peptide internalization after 60 -minute incubation at $i 4^{\circ} \mathrm{C}$ or ii $37^{\circ} \mathrm{C}$ (a)

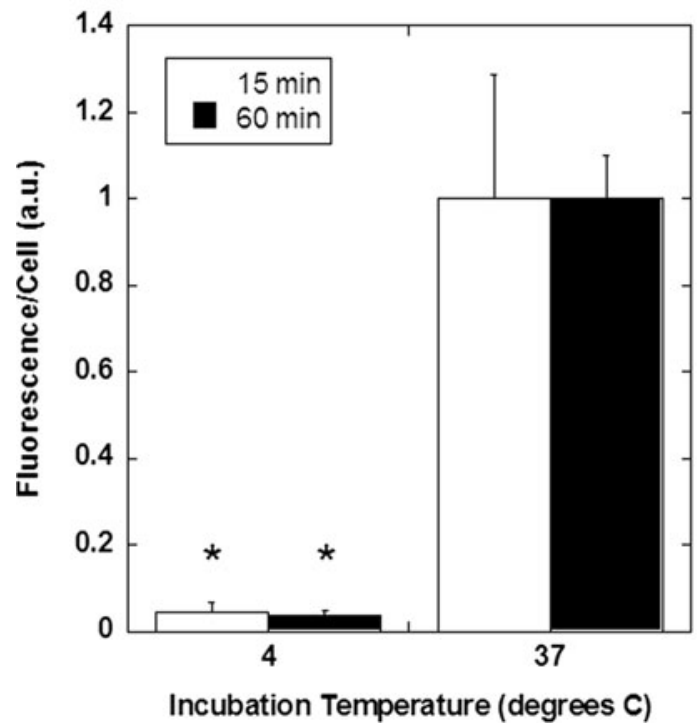

(b)
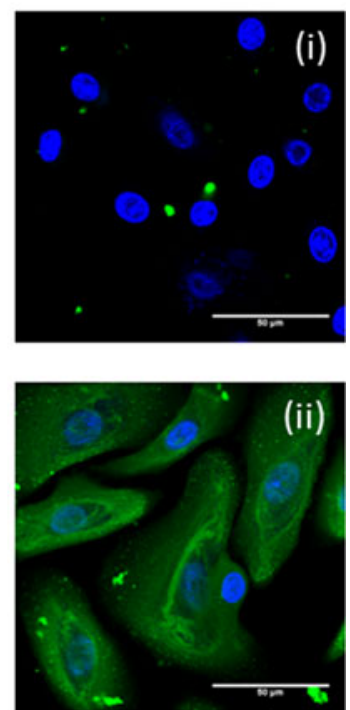

stimulation or inhibition of macropinocytosis did result in a significant increase (3.6 \pm 1.3 -fold) or decrease $(71.1 \pm 11.3 \%)$ in dextran internalization, respectively, relative to dextran internalization in the absence of EGF and EIPA. These observations indicate that at least some fraction of SPACETM peptide is internalized by non-macropinocytosis pathways at higher concentrations $(\mathrm{mg} / \mathrm{mL})$.

\section{Studies Using Endocytosis Inhibitors}

To gain additional insight into how SPACE ${ }^{\mathrm{TM}}$ peptide mediates internalization and cytoplasmic localization, the effects of chemical inhibitors of internalization were analyzed (Figs. 6a and 7a). Inhibition of caveolin-dependent endocytosis with nystatin had no significant effect on SPACETM peptide internalization (Fig. 6a). Additionally, there was no observable
Fig. 4 SPACE ${ }^{\mathrm{TM}}$ peptide colocalized with dextran in punctate structures, however, extensive diffuse staining of SPACE ${ }^{\mathrm{TM}}$ peptide, absent of dextran, was also observed. a Representative images of HEKa cells incubated with $i$ media only (control), ii TAMRA-dextran (red), iii FITCSPACETM peptide (green), or iv TAMRA-dextran and FITCSPACETM peptide. Nuclei are stained with Hoechst 33342 (blue). Arrows indicate colocalization (yellow). b Internalization of $i$ TAMRAdextran and $i i$ FITC-SPACE ${ }^{\mathrm{TM}}$ peptide was quantified with and without co-incubation. Error bars represent mean $+\mathrm{SD}$ for $n=3$. ${ }^{*} p<0.05$

\section{(a)}
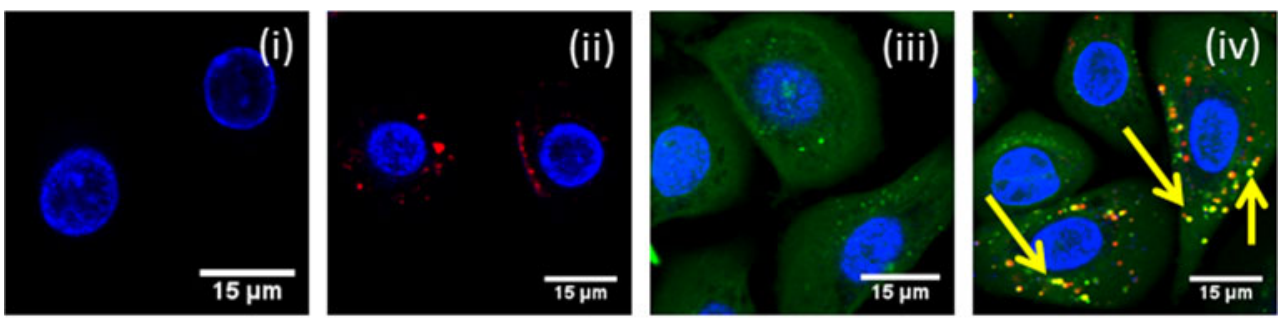

(b)

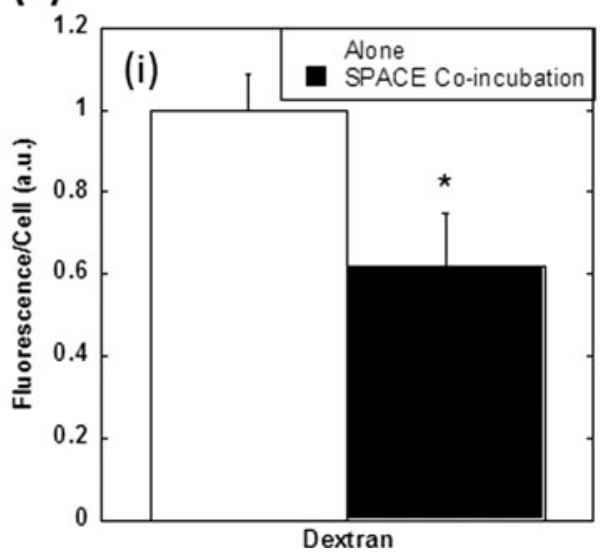

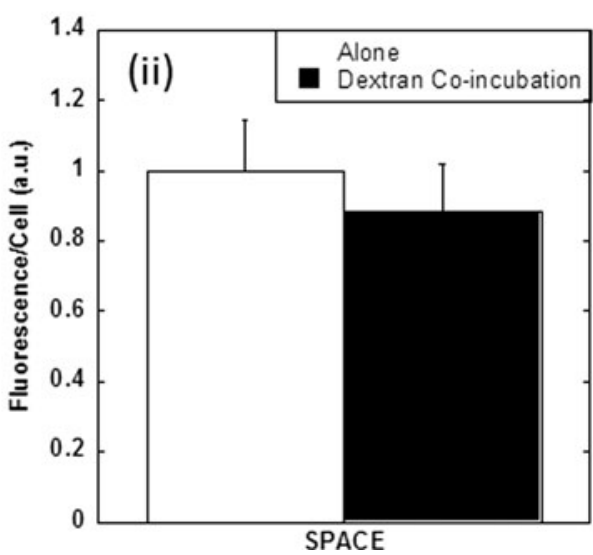


Fig. 5 Incubation with SPACE ${ }^{\mathrm{TM}}$ peptide does not show actin rearrangement characteristic of macropinocytosis stimulation. a Representative images of actin (red) after incubation with $(i)$ media only (control), ii dextran, iii SPACETM peptide, $i v$ EGF (macropinocytosis stimulant), and $v$ EIPA (macropinocytosis inhibitor). Arrows indicate membrane ruffling characteristic of macropinocytosis stimulation. b Internalization of $i$ TAMRAdextran or ii FITC-SPACETM peptide incubated with a macropinocytosis stimulant $(E G F)$ or inhibitor $(E I P A)$ relative to incubation in media only. Error bars represent mean $+\mathrm{SD}$ for $n=3 .{ }^{*} p<0.05$

\section{(a)}
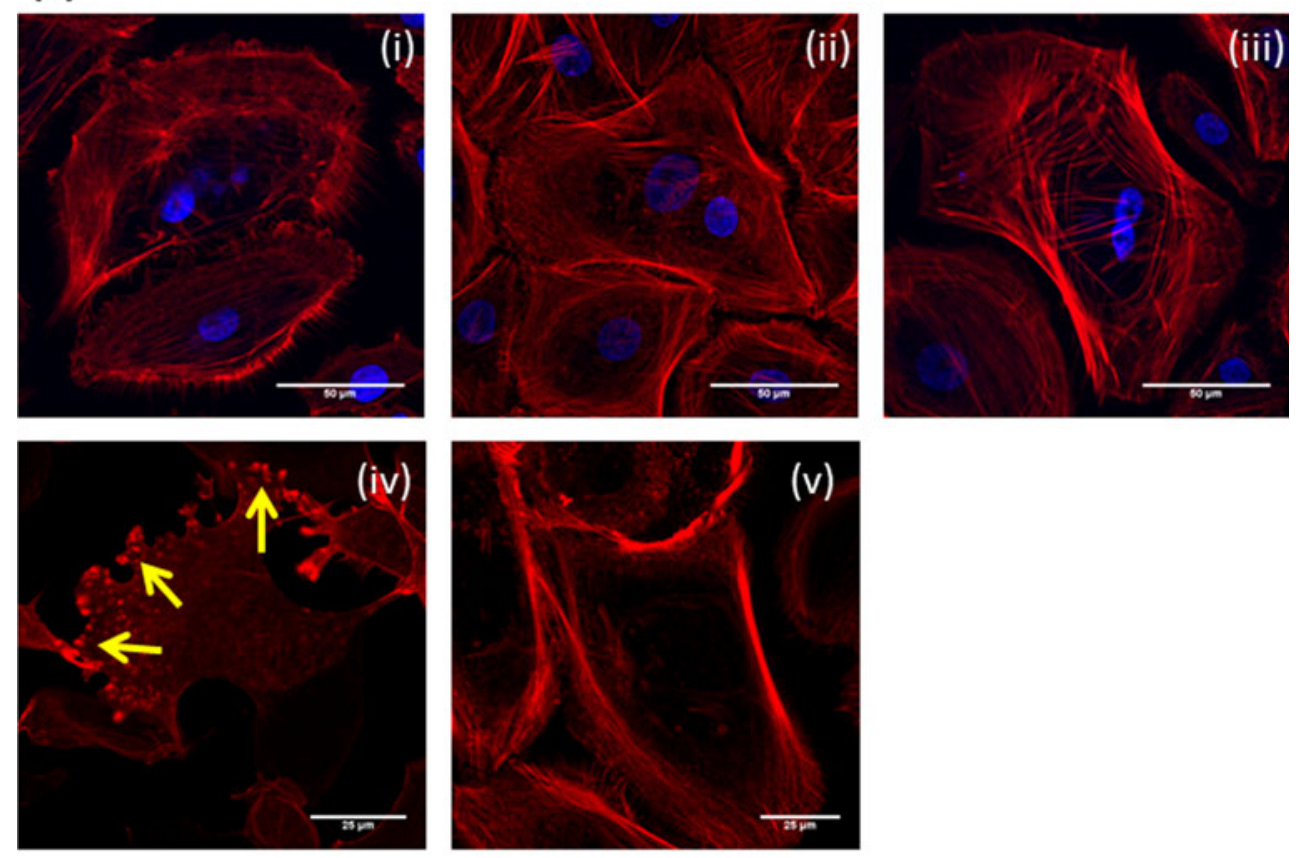

(b)
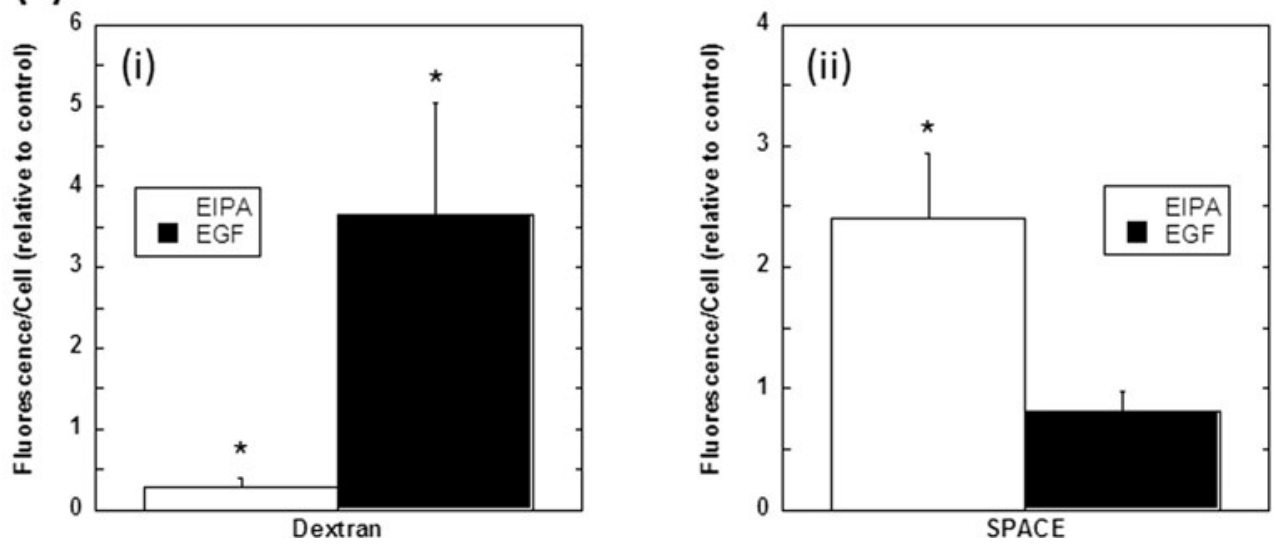

dependence on actin (inhibited by cytochalasin D) or tubulin (inhibited by nocodazole), as well as no observable dependence on cholesterol (sequestered by M $\beta C D$ ) (Fig. 6a). The effect of these inhibitors was verified using FITC-transferrin as a control (Figs. $6 \mathrm{~b}$ and $7 \mathrm{~b}$ ). Further, actin and microtubule depolymerization by cytochalasin $\mathrm{D}$ and nocodazole, respectively, was confirmed by visualization with confocal microscopy (Fig. 6c). Incubation with inhibitors at the specified concentrations did not result in any noticeable cell toxicity or morphological abnormalities. Moreover, they did not result in any significant membrane perturbation, as verified by a lack of nuclei staining by EtBr.

Dependence on clathrin-mediated endocytosis was most striking. Inhibition of clathrin-mediated endocytosis using a variety of chemical inhibitors resulted in significant increase in SPACE ${ }^{\mathrm{TM}}$ peptide internalization (Fig. 7a). Inhibition with chlorpromazine resulted in a $4.9 \pm 0.8$-fold increase in SPACE ${ }^{\mathrm{TM}}$ peptide internalization. Similarly, inhibition with dynasore, genistein, and primaquine resulted in $6.5 \pm 0.7$-fold, $4.6 \pm 0.5$-fold, and 4.6 \pm 1.4 -fold enhancements in SPACE ${ }^{\mathrm{TM}}$ peptide internalization, respectively. However, inhibition of clathrin-mediated endocytosis, indicated by internalization of FITC-transferrin, did not correlate directly with an increase in SPACETM peptide internalization. Specifically, inhibition with monodansylcadaverine resulted in a significant decrease $(92.7 \pm 1.5 \%)$ in FITCtransferrin internalization; however, it had no significant effect on SPACETM peptide internalization suggesting the observed pathway is not simply compensatory for inhibition of clathrin-mediated endocytosis. No appreciable toxicity or membrane disruption was observed after incubation with inhibitors. 
Fig. 6 Chemical inhibition analysis of SPACETM peptide internalization pathway. a Internalization of FITCSPACE ${ }^{\mathrm{TM}}$ peptide. $\mathbf{b}$ Internalization of FITCtransferrin (control).

Internalization was normalized to FITC-SPACE ${ }^{\mathrm{TM}}$ peptide or FITCtransferrin incubated with HEKa cells in the absence of inhibitor. Error bars represent mean $+\mathrm{SD}$ for $n=3 .{ }^{*} p<0.05$. c

Representative images of $i$ native actin, $i i$ actin in the presence of inhibitor, iii native tubulin, and $i v$ tubulin in the presence of inhibitor
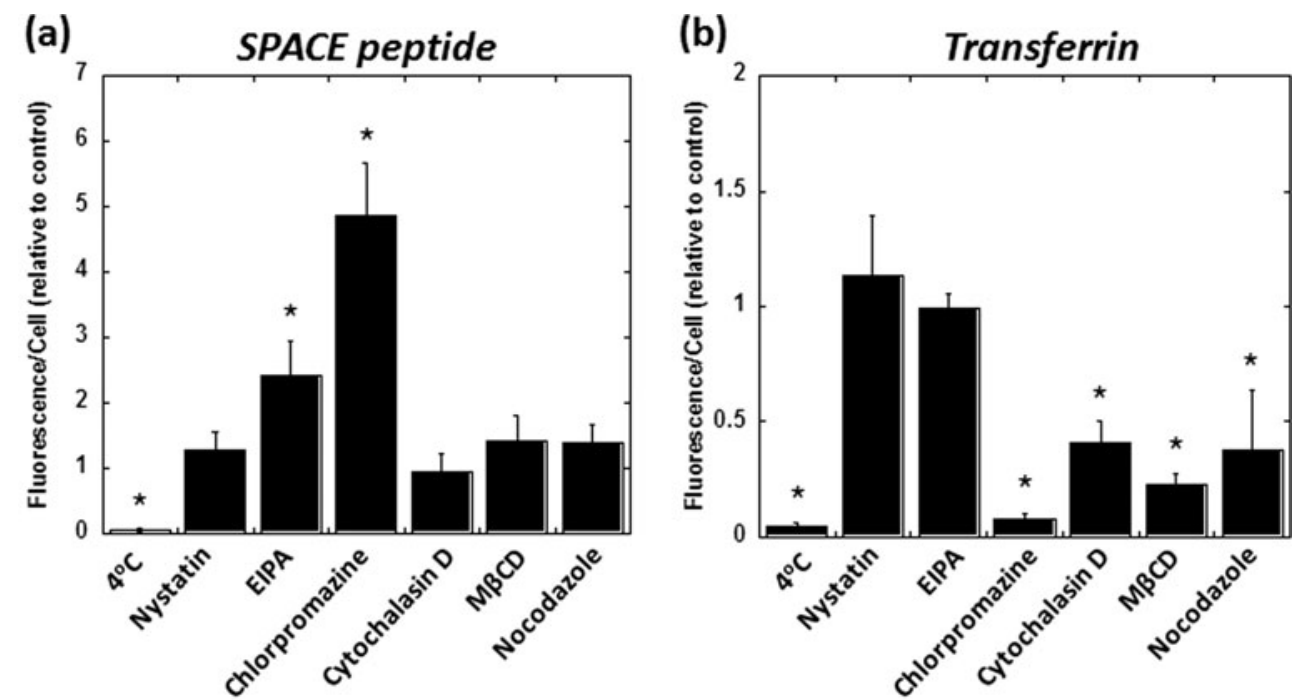

(c)
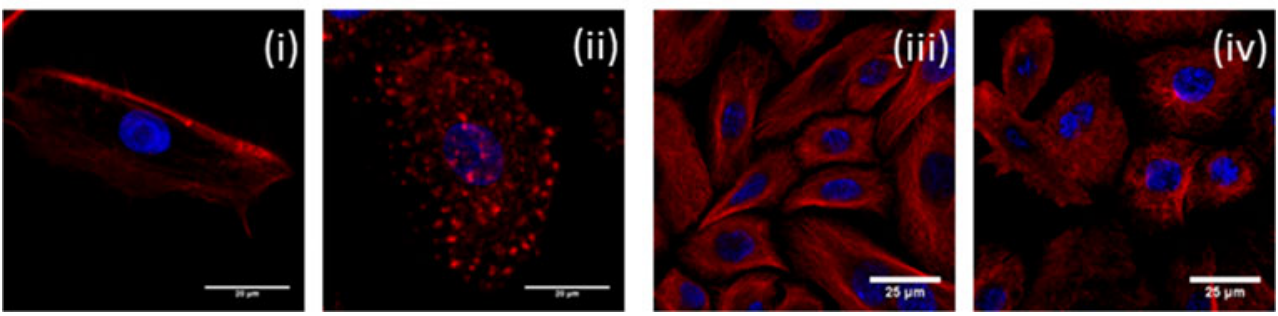

\section{Discussion}

Keratinocytes constitute the majority of the epidermis, which is the first viable tissue layer in the skin. Therefore, they are the first living cell-type to interact with drugs applied on the skin and a targeted cell-type for combating skin-related disease. However, delivering drugs through the skin and into keratinocytes remains a significant challenge due to transport barriers posed by both the stratum corneum (SC) and cell membrane. To overcome these transport barriers, peptides hold great potential due to their simplicity and diversity, and several peptides have been identified that enhance transport
Fig. 7 Chemical inhibition analysis of clathrin-mediated endocytosis. a Internalization of FITC-SPACETM peptide in the presence of inhibitors.

Internalization was normalized to FITC-SPACETM peptide

internalization in the absence of inhibitors. b Internalization of FITC-transferrin in the presence of inhibitors. Internalization was normalized to FITC-transferrin internalization in the absence of inhibitors. Error bars represent mean $+\mathrm{SD}$ for $n=3 . * p<0.01$ (a)

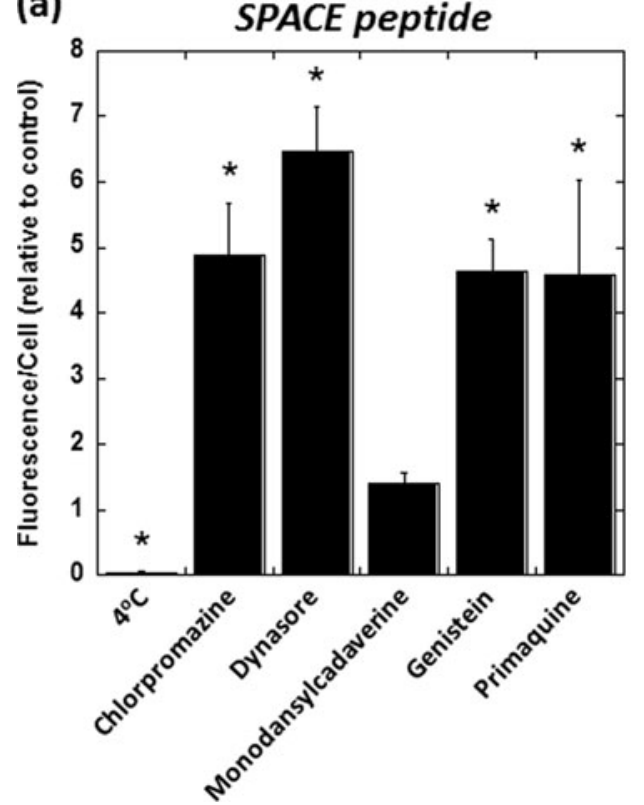

(b)

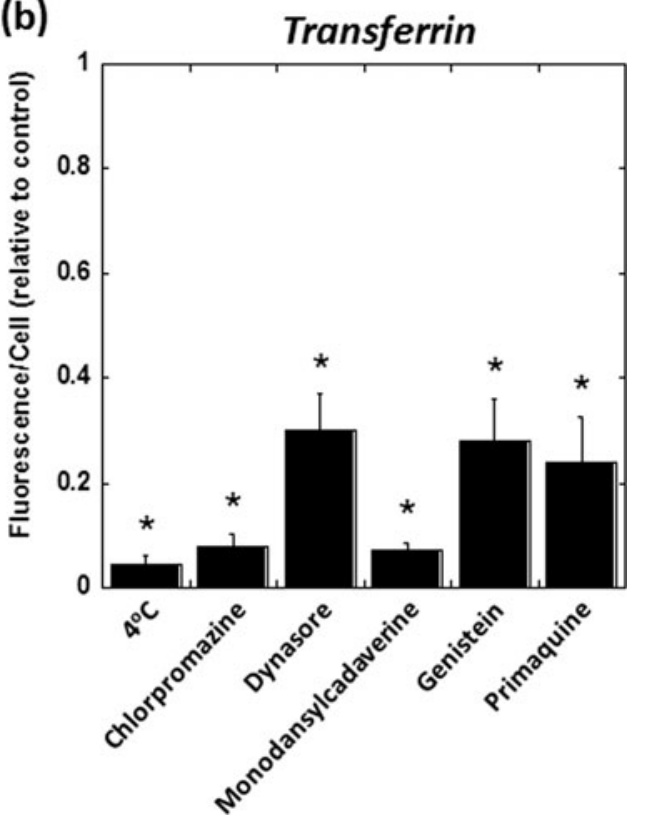


across both the SC and cell membrane including TAT, poly-R, SPACE ${ }^{\mathrm{TM}}$ peptide, and penetratin [12-15].

Nevertheless, a critical next step towards developing effective peptide-based, topical drug delivery platforms is to better understand how cell-penetrating peptides (CPPs) interact with keratinocytes. Although much effort has been spent over the last few decades trying to decipher the pathways responsible for CPP internalization in a variety of cell-types [27], and better understand the factors that influence those pathways, controversy surrounding the biological mechanisms that govern CPP internalization and intracellular localization remains [28]. Much of this controversy seems to arise from the fact that CPP internalization is highly dependent on the cell-type and concentration, and studies exploring CPP internalization in keratinocytes at concentrations relevant for topical delivery are severely lacking.

Previous studies have shown that topical application of $50 \mathrm{mg} / \mathrm{mL}$ SPACE ${ }^{\mathrm{TM}}$ peptide is required for maximum macromolecule delivery into the skin, and a fraction of applied SPACE ${ }^{\mathrm{TM}}$ peptide enters the viable epidermis and dermis [16-19]. Accordingly, we sought to explore SPACETM peptide internalization in keratinocytes within this clinically relevant concentration range $(\sim \mathrm{mg} / \mathrm{mL})$. SPACETM peptide was discovered due to its ability to traverse the stratum corneum, and therefore, could be expected to interact uniquely with keratinocytes. In addition, SPACETM peptide is chemically unique compared to most other CPPs due to its neutral charge and relative hydrophilicity (Table 2). Moreover, whereas TAT, poly-R, and penetratin have been shown to be toxic at concentrations required for drug delivery through the skin [29], SPACE $^{\mathrm{TM}}$ peptide is non-toxic at concentrations as high as $10 \mathrm{mg} / \mathrm{mL}$ [19].

First, we studied SPACETM peptide association with the cell membrane. Interestingly, we observed rapid and extensive association with the cell membrane (Fig. 1a). Moreover, association appears to be specific in nature (Fig. 1c). There was no observable difference in internalization when SPACE ${ }^{\mathrm{TM}}$ peptide was incubated with molar excess heparin sulfate, which has been shown to significantly reduce the internalization efficacy of positively charged CPPs like TAT and poly-R [28, 37, 38]. Further, there was no observable difference in internalization when SPACE ${ }^{\mathrm{TM}}$ peptide was incubated with molar excess FBS, which has been shown to significantly reduce the internalization efficacy of amphipathic CPPs like penetratin and model amphipathic peptide (MAP) [28]. Together, these results suggest SPACE ${ }^{\mathrm{TM}}$ peptide may bind specifically to an extracellular, membrane-anchored, or transmembrane protein.

Mass spectrometry revealed 244 potential targets for SPACE ${ }^{\mathrm{TM}}$ peptide, and a subset of these based on the frequency of identified peptide fragments are given (Table 1). The highest frequency proteins were structural proteins including actin, tubulin, and keratin. This result is consistent with the observations made while studying membrane association and internalization. In both cases, we observed clear filamentouslike staining suggestive of binding to extracellular as well as intracellular structural proteins (Fig. 1).

The results are consistent with earlier studies indicating association of SPACETM peptide with keratin. Specifically, we recently reported computational studies on association of SPACE ${ }^{\mathrm{TM}}$ peptide to keratin and experimentally confirmed the binding constant through chromatography [39]. Further, experimental and computational studies also revealed a direct correlation between keratin binding and transport enhancement through the skin [19]. Keratin 1, Keratin 5, and Keratin 14 are the major keratin subtypes present in epidermal keratinocytes [40] and were identified here as potential binding partners of SPACE ${ }^{\mathrm{TM}}$ peptide. In addition, SPACE ${ }^{\mathrm{TM}}$ peptide shows extensive sequence homology to a Staphylococcus epidermidis surface protein [12]. Bacterial surface proteins are responsible for binding to extracellular matrix proteins during infection, and recently the binding site for a Staphylococcus aureus surface protein with Keratin 10 was crystallized [41]. Similar function could be expected from S. epidermidis surface proteins as well. Furthermore, antibodies for keratin have been shown to result in similar staining patterns as observed here [42]. Binding to keratin could result in a signaling response leading to keratin turnover or internalization. Cells are known to accept cues from their extracellular environment leading to migration, receptor internalization, differentiation, etc. This may explain why concentrations of milligram/ milliliter of unconjugated SPACE ${ }^{\mathrm{TM}}$ peptide resulted in enhanced internalization and localization of FITC [18].

In contrast to association with the cell membrane, longer kinetics was observed for internalization. The maximum internalized concentration of SPACE TM peptide occurs after 15$30 \mathrm{~min}$, which suggests an active internalization mechanism (Fig. 1b). For example, intracellular concentrations of TAT have been shown to equilibrate within a few minutes after incubation for concentration regimes where internalization is dominated by passive diffusion [34]. SPACE ${ }^{\mathrm{TM}}$ is a small, cyclic peptide, and it was discovered through skin permeation experiments. Thus, it is highly likely to resist proteases during the short incubation times with cells used in this study. The likelihood of eventual enzymatic degradation in lysosomes, however, is not clear. While such potential degradation may impact the long-term fate of the peptide, we hypothesize that it is unlikely to play a role in cell entry.

FITC intensity is known to be dependent on $\mathrm{pH}$ and concentration; thus, conclusions should not be reached based on the absolute intensity of fluorescence in cells. Previous experiments have been also performed over a wide range of SPACETM concentration in the range of $0.1-10 \mathrm{mg} / \mathrm{ml}$, and internalization was found to increase with increasing peptide concentration [18]. Therefore, contributions of FITC selfquenching are not expected to have a significant influence on measurements or conclusions in the study. 
Table 2 Chemical composition of SPACETM peptide is unique among majority of cell-penetrating peptides studied to-date

\begin{tabular}{|c|c|c|c|}
\hline Name & Sequence & pI & Ref. \\
\hline $\mathrm{SPACE}^{\mathrm{TM}}$ & ACTGSTQHQCG & 6.72 & $(12)$ \\
\hline PolyArginine (R8) & RRRRRRRR & 13.35 & $(30)$ \\
\hline TAT (49-57) & RKKRRQRRR & 13.2 & $(30)$ \\
\hline PEP-1 & KETWWETWWTEWSQPKKRKV & 10.62 & $(31)$ \\
\hline Penetratin & RQIKIWFQNRRMKWKK & 12.83 & $(32)$ \\
\hline Transportan & GWTLNSAGYLLGKINLKALAALAKKIL & 10.87 & $(32)$ \\
\hline VP22 & DAATATRGRSAASRPTERPRAPARSASRPRRPVD & 12.6 & (33) \\
\hline $\operatorname{Rev}(34-50)$ & TRQARRNRRRRWRERQR & 13.1 & $(30)$ \\
\hline Antp(43-58) & RQIKIYFQNRRMKWKK & 12.28 & (34) \\
\hline FHV (35-49) & RRRRNRTRRNRRRVR & 13.5 & $(30)$ \\
\hline MAP & KLALKLALKALKAALKLA & 11.4 & $(32)$ \\
\hline MTS & AAVALLPAVLLALLP & 5.28 & $(30)$ \\
\hline BMV Gag (7-25) & KMTRAQRRAAARRNRWTAR & 13.28 & $(30)$ \\
\hline HTLV-II Rex (4-16) & TRRQRTRRARRNR & 13.35 & $(30)$ \\
\hline CCMV Gag (7-25) & KLTRAQRRAAARKNKRNTR & 13.21 & $(30)$ \\
\hline P22 N (14-30) & NAKTRRHERRRKLAIER & 12.51 & $(30)$ \\
\hline MPG & GALFLGFLGAAGSTMGAWSQPKSKRKV & 11.93 & $(32)$ \\
\hline VT5 & DPKGDPKGVTVTVTVTVTGKGDPKPD & 5.78 & $(35)$ \\
\hline EB1 & LIRLWSHLIHIWFQNRRLKWKKK & 12.83 & $(36)$ \\
\hline $\mathrm{pVEC}$ & LLIILRRRIRKQAHAHSK & 12.98 & (36) \\
\hline CADY & GLWRALWRLLRSLWRLLWKA & 12.98 & $(36)$ \\
\hline PreS2-TLM & PLSSIFSRIGDG & 5.55 & $(31)$ \\
\hline Calcitonin-derived & LGTYTQDFNKFHTFPQTAIGVGAP & 6.75 & $(31)$ \\
\hline SynB1 & RGGRLSYSRRRFSTSTGRA & 12.8 & $(31)$ \\
\hline Human Integrin $\beta 3$ & VTVLALGALAGVGVG & 5.28 & $(31)$ \\
\hline
\end{tabular}

Black, green, blue, and red letters represent polar uncharged, hydrophobic, basic, and acidic amino acids, respectively 
Active internalization was confirmed by comparing internalization at $37{ }^{\circ} \mathrm{C}$ to internalization at $4{ }^{\circ} \mathrm{C}$. Specifically, internalization was nearly completely eliminated at $4{ }^{\circ} \mathrm{C}$ (Fig. 3). Although low temperatures would be expected to result in a decrease in passive diffusion across the cell membrane due to a decrease in lipid fluidization, the extent of transport reduction would be proportional to the change in diffusion coefficient with some additional contribution from changes in cell membrane binding and partitioning into the lipid bilayer. For example, Zaro and Shen showed a $40 \%$ reduction in passive diffusion of oligoarginine into $\mathrm{CHO}$ cells following incubation at $4{ }^{\circ} \mathrm{C}$ [43]. Our results, on the other hand, show extensive $(>95 \%)$ reduction in internalization that cannot be accounted for by physical effects due to decreased temperature. In addition, the reduction is independent of incubation time. Therefore, some energy-dependent process is highly likely involved.

Active internalization suggests occurrence of endocytosis and nearly all previously discovered CPPs have been shown to be internalized by endocytosis, with the most common endocytosis pathway being macropinocytosis. This is a particularly common observation when sub-micromolar CPP concentrations were studied. Furthermore, SPACE ${ }^{\mathrm{TM}}$ peptide was already shown to predominantly exploit macropinocytosis at microgram/milliliter concentrations [12], and macropinosomes are known to be leaky [44], which could explain the extensive diffuse cytoplasmic staining observed.

However, SPACETM peptide does not appear to predominantly exploit macropinocytosis at higher concentrations (mg/ $\mathrm{mL}$ ) studied here. For example, co-incubation with dextran, a marker of macropinocytosis, resulted in significant diffuse staining of SPACE ${ }^{\mathrm{TM}}$ peptide while dextran was retained in punctate structures (Fig. 4a). There was some co-localization between SPACETM peptide and dextran in punctate spots, which suggests that SPACETM peptide is internalized to some extent by macropinocytosis; however, it does not appear to be the dominating pathway taken by SPACE ${ }^{\mathrm{TM}}$ peptide at higher concentrations $(\mathrm{mg} / \mathrm{mL})$. SPACETM peptide could potentially stimulate macropinocytosis and subsequently perturb the macropinosome leading to release into the cytosol; however, we would expect some diffuse staining by dextran as well since the molecular weights of dextran and SPACETM peptide used in this study were similar. Moreover, the kinetics of internalization is faster than what would be expected for macropinocytosis. Here, intracellular concentration of SPACETM peptide maximized after 15-30 min, whereas macropinocytosis is typically reported to show maximum internalization upwards of an hour [45]. SPACETM peptide could be stimulating macropinocytosis leading to faster internalization; however, if that were the case, we would expect a corresponding increase in overall dextran internalization. For example, TAT peptide was shown to induce macropinocytosis [24] and enhance internalization of dextran during co- incubation [46]. In contrast, an increase was not observed here; instead, a significant decrease was observed, suggesting SPACETM peptide may actually compete with dextran for internalization by macropinocytosis without stimulating macropinocytosis (Fig. 4b). As additional confirmation that SPACETM peptide does not stimulate macropinocytosis, actin rearrangement was studied. Actin rearrangement is characteristic of macropinocytosis and various CPPs, and drug carriers have been shown to initiate actin rearrangement during macropinocytosis stimulation [24, 47, 48]. EIPA was used to inhibit macropinocytosis, and EGF was used to activate macropinocytosis. In line with previous observations, SPACETM peptide does not induce actin rearrangement (Fig. 5a).

To gain further insight into how SPACETM peptide mediates internalization and cytoplasmic localization, the effects of chemical inhibitors of endocytosis were analyzed. The lack of effects on SPACETM peptide internalization after inhibition of internal trafficking machinery (Fig. 6a), together with the lack of diffuse staining by dextran during co-incubation with SPACE ${ }^{\mathrm{TM}}$ peptide (Fig. 4a), is striking. Dependence on clathrin-mediated endocytosis was most striking. Inhibition of clathrin-mediated endocytosis with a variety of chemical inhibitors resulted in significant increases in SPACE ${ }^{\mathrm{TM}}$ peptide internalization (Fig. 7a). This suggests the mechanism of SPACE ${ }^{\mathrm{TM}}$ peptide entry may be compensatory for clathrinmediated endocytosis. Alternatively, SPACE ${ }^{\mathrm{TM}}$ peptide internalization may compete for resources of other endocytosis pathways in some way. Indeed, this could explain why we observed significant, albeit differing, enhancements in internalization of SPACETM peptide when various endocytosis pathways were inhibited with EIPA, chlorpromazine, dynasore, genistein, and primaquine, each with their own mechanism of action on various stages of endocytosis pathways [21].

Taken together, our results demonstrate an internalization profile that is quite different from studies with other CPPs. We show nearly instantaneous membrane binding (saturates after $\sim 1 \mathrm{~min}$ ) and fast internalization relative to endocytosis, but slow internalization relative to passive transport, that saturates after 15-30 min. The data presented here is consistent with earlier findings of association of SPACE ${ }^{\mathrm{TM}}$ peptide with keratin. It is possible, however, that another protein present at a lower concentration may also be at play and could not be identified due to limits of fluorescence detection. Assessment of mechanisms in other cell types is also of interest and should be the focus of future studies.

Acknowledgments We thank the NRI-MCDB Microscopy Facility for access to the Olympus Fluoview 1000 Spectral confocal microscope, which was supported by NIH Grant 1S10 OD010610-01A1. We thank Dr. Charles Haitjema and Professor Michelle O'Malley for their helpful guidance and expertise with SDS-PAGE and Western blot. SM is a shareholder and advisor of CTX technologies. 


\section{References}

1. Barker JNWN, Mitra RS, Griffiths CEM, Dixit VM, Nickoloff BJ. Keratinocytes as initiators of inflammation. Lancet. 1991;337:211-4.

2. Albanesi $\mathrm{C}, \mathrm{De}$ Pità $\mathrm{O}$, Girolomoni G. Resident skin cells in psoriasis: a special look at the pathogenetic functions of keratinocytes. Clin Dermatol. 2007;25:581-8.

3. Werfel T. The role of leukocytes, keratinocytes, and allergenspecific IgE in the development of atopic dermatitis. J Investig Dermatol. 2009;129:1878-91.

4. Eming SA, Krieg T, Davidson JM. Inflammation in wound repair: molecular and cellular mechanisms. J Investig Dermatol. 2007;127: 514-25.

5. Martin P. Wound healing - aiming for perfect skin regeneration. Science. 1997;276:75-81

6. Payne AS, Hanakawa Y, Amagai M, Stanley JR. Desmosomes and disease: pemphigus and bullous impetigo. Curr Opin Cell Biol. 2004; $16: 536-43$

7. Trautmann A, Akdis M, Schmid-Grendelmeier P, Disch R, Bröcker E-B, Blaser K, et al. Targeting keratinocyte apoptosis in the treatment of atopic dermatitis and allergic contact dermatitis. J Allergy Clin Immunol. 2001;108:839-46.

8. Petek LM, Fleckman P, Miller DG. Efficient KRT14 Targeting and functional characterization of transplanted human keratinocytes for the treatment of epidermolysis bullosa simplex. Mol Ther J Am Soc Gene Ther. 2010;18:1624-32.

9. Brown MB, Martin GP, Jones SA, Akomeah FK. Dermal and transdermal drug delivery systems: current and future prospects. Drug Deliv. 2006;13:175-87.

10. Prausnitz MR, Mitragotri S, Langer R. Current status and future potential of transdermal drug delivery. Nat Rev Drug Discov. 2004;3:115-24.

11. Rajendran L, Knolker HJ, Simons K. Subcellular targeting strategies for drug design and delivery. Nat Rev Drug Discov. 2010;9:29-42.

12. Hsuand T, Mitragotri S. Delivery of siRNA and other macromolecules into skin and cells using a peptide enhancer. Proc Natl Acad Sci U S A. 2011;108:15816-21.

13. Lopes LB, Brophy CM, Furnish E, Flynn CR, Sparks O, Komalavilas $\mathrm{P}$, et al. Comparative study of the skin penetration of protein transduction domains and a conjugated peptide. Pharm Res. 2005;22:750-7.

14. Rothbard JB, Garlington S, Lin Q, Kirschberg T, Kreider E, McGrane PL, et al. Conjugation of arginine oligomers to cyclosporin A facilitates topical delivery and inhibition of inflammation. Nat Med. 2000;6:1253-7.

15. Nasrollahi SA, Taghibiglou C, Azizi E, Farboud ES. Cellpenetrating peptides as a novel transdermal drug delivery system. Chem Biol Drug Des. 2012;80:639-46.

16. Chen M, Kumar S, Anselmo AC, Gupta V, Slee DH, Muraski JA, et al. Topical delivery of cyclosporine A into the skin using SPACEpeptide. J Control Release. 2015;199:190-7.

17. Chen M, Gupta V, Anselmo AC, Muraski JA, Mitragotri S. Topical delivery of hyaluronic acid into skin using SPACE-peptide carriers. J Contro Release Off J Control Release Soc. 2014;173:67-74.

18. Chen M, Zakrewsky M, Gupta V, Anselmo AC, Slee DH, Muraski JA, et al. Topical delivery of siRNA into skin using SPACE-peptide carriers. J Control Release. 2014;179:33-41.

19. Kumar S, Zakrewsky M, Chen M, Menegatti S, Muraski JA, Mitragotri S. Peptides as skin penetration enhancers: mechanisms of action. J Control Release. 2015;199:168-78.

20. Kamentsky L, Jones TR, Fraser A, Bray MA, Logan DJ, Madden $\mathrm{KL}$, et al. Improved structure, function and compatibility for Cell Profiler: modular high-throughput image analysis software. Bioinformatics. 2011;27:1179-80.
21. Ivanov AI. Pharmacological inhibition of endocytic pathways: is it specific enough to be useful? Exocytosis and Endocytosis. Springer; 2008. pp. 15-33.

22. Cascales L, Henriques ST, Kerr MC, Huang Y-H, Sweet MJ, Daly NL, et al. Identification and characterization of a new family of cellpenetrating peptides cyclic cell-penetrating peptides. J Biol Chem. 2011;286:36932-43.

23. Jones AT. Macropinocytosis: searching for an endocytic identity and role in the uptake of cell penetrating peptides. J Cell Mol Med. 2007;11:670-84.

24. Nakase I, Niwa M, Takeuchi T, Sonomura K, Kawabata N, Koike Y, et al. Cellular uptake of arginine-rich peptides: roles for macropinocytosis and actin rearrangement. Mol Ther J Am Soc Gene Ther. 2004;10:1011-22.

25. Sugita T, Yoshikawa T, Mukai Y, Yamanada N, Imai S, Nagano K, et al. Comparative study on transduction and toxicity of protein transduction domains. Br J Pharmacol. 2008;153:1143-52.

26. Khalil IA, Kogure K, Futaki S, Harashima H. High density of octaarginine stimulates macropinocytosis leading to efficient intracellular trafficking for gene expression. J Biol Chem. 2006;281: 3544-51.

27. Patel LN, Zaro JL, Shen WC. Cell penetrating peptides: intracellular pathways and pharmaceutical perspectives. Pharm Res. 2007;24:1977-92.

28. Jonesand AT, Sayers EJ. Cell entry of cell penetrating peptides: tales of tails wagging dogs. J Control Release Off J Control Release Soc. 2012;161:582-91.

29. Kilk K, Mahlapuu R, Soomets U, Langel U. Analysis of in vitro toxicity of five cell-penetrating peptides by metabolic profiling. Toxicology. 2009;265:87-95.

30. Futaki S. Membrane-permeable arginine-rich peptides and the translocation mechanisms. Adv Drug Deliv Rev. 2005;57:547-58.

31. Fischer R, Fotin-Mleczek M, Hufnagel H, Brock R. Break on through to the other side-biophysics and cell biology shed light on cell-penetrating peptides. Chembiochem Eur J Chem Biol. 2005;6:2126-42.

32. Zorkoand M, Langel U. Cell-penetrating peptides: mechanism and kinetics of cargo delivery. Adv Drug Deliv Rev. 2005;57:529-45.

33. Elliottand G, O'Hare P. Intercellular trafficking and protein delivery by a herpesvirus structural protein. Cell. 1997;88:223-33.

34. Duchardt F, Fotin-Mleczek M, Schwarz H, Fischer R, Brock R. A comprehensive model for the cellular uptake of cationic cellpenetrating peptides. Traffic. 2007;8:848-66.

35. Oehlke J, Beyermann M, Wiesner B, Melzig M, Berger H, Krause E, et al. Evidence for extensive and non-specific translocation of oligopeptides across plasma membranes of mammalian cells. Biochim Biophys Acta. 1997;1330:50-60.

36. Eiriksdottir E, Konate K, Langel U, Divita G, Deshayes S. Secondary structure of cell-penetrating peptides controls membrane interaction and insertion. Biochim Biophys Acta. 2010;1798:1119-28.

37. Dix AV, Fischer L, Sarrazin S, Redgate CPH, Esko JD, Tor Y. Cooperative, heparan sulfate-dependent cellular uptake of dimeric guanidinoglycosides. Chembiochem Eur J Chem Biol. 2010;11: 2302-10.

38. Sawantand $\mathrm{R}$, Torchilin V. Intracellular transduction using cellpenetrating peptides. Mol BioSyst. 2010;6:628-40.

39. Menegatti S, Zakrewsky M, Kumar S, De Oliveira JS, Muraski JA, Mitragotri S. De novo design of skin-penetrating peptides for enhanced transdermal delivery of peptide drugs. Advanced Healthcare Materials:n/a-n/a. 2016.

40. Mall R, Franke WW, Schiller DL, Geiger B, Krepler R. The catalog of human cytokeratins-patterns of expression in normal epithelial, tumors, and cultured cells. Cell. 1982;31:11-24.

41. Ganesh VK, Barbu EM, Deivanayagam CC, Le B, Anderson AS, Matsuka YV, et al. Structural and biochemical characterization of 
Staphylococcus aureus clumping factor B/ligand interactions. J Biol Chem. 2011;286:25963-72.

42. Ditzel HJ, Garrigues U, Andersen CB, Larsen MK, Garrigues HJ, Svejgaard A, et al. Modified cytokeratins expressed on the surface of carcinoma cells undergo endocytosis upon binding of human monoclonal antibody and its recombinant Fab fragment. Proc Natl Acad Sci U S A. 1997;94:8110-5.

43. Zaroand JL, Shen W-C. Quantitative comparison of membrane transduction and endocytosis of oligopeptides. Biochem Biophys Res Commun. 2003;307:241-7.

44. Meier O, Boucke K, Hammer SV, Keller S, Stidwill RP, Hemmi S, et al. Adenovirus triggers macropinocytosis and endosomal leakage together with its clathrin-mediated uptake. J Cell Biol. 2002;158: 1119-31.
45. Mager I, Eiriksdottir E, Langel K, El Andaloussi S, Langel U. Assessing the uptake kinetics and internalization mechanisms of cell-penetrating peptides using a quenched fluorescence assay. Biochim Biophys Acta. 2010;1798:338-43.

46. Lee YJ, Erazo-Oliveras A, Pellois JP. Delivery of macromolecules into live cells by simple co-incubation with a peptide. Chembiochem Eur J Chem Biol. 2010;11:325-30.

47. Nakase I, Tadokoro A, Kawabata N, Takeuchi T, Katoh H, Hiramoto $\mathrm{K}$, et al. Interaction of arginine-rich peptides with membraneassociated proteoglycans is crucial for induction of actin organization and macropinocytosis. Biochemistry. 2007;46:492-501.

48. Love KT, Mahon KP, Levins CG, Whitehead KA, Querbes W, Dorkin JR, et al. Lipid-like materials for low-dose, in vivo gene silencing. Proc Natl Acad Sci U S A. 2010;107:1864-9. 